\title{
Predicting Spinel Disorder and its Effect on Oxygen Transport Kinetics in Hercynite
}

Ryan M. Trottier ${ }^{1}$, Zachary J. L. Bare ${ }^{1}$, Samantha L. Millican ${ }^{1}$, and Charles B. Musgrave $e^{1,2,3,4,{ }^{*}}$

'University of Colorado Boulder, Department of Chemical and Biological Engineering, Boulder, Colorado, 80309, United States

${ }^{2}$ University of Colorado Boulder, Department of Chemistry, Boulder, Colorado, 80309, United States

3Materials Science and Engineering Program, University of Colorado, Boulder, Colorado 80309, United States

4Renewable and Sustainable Energy Institute, University of Colorado, Boulder, Colorado 80309, United States

*Email: charles.musgrave@colorado.edu 

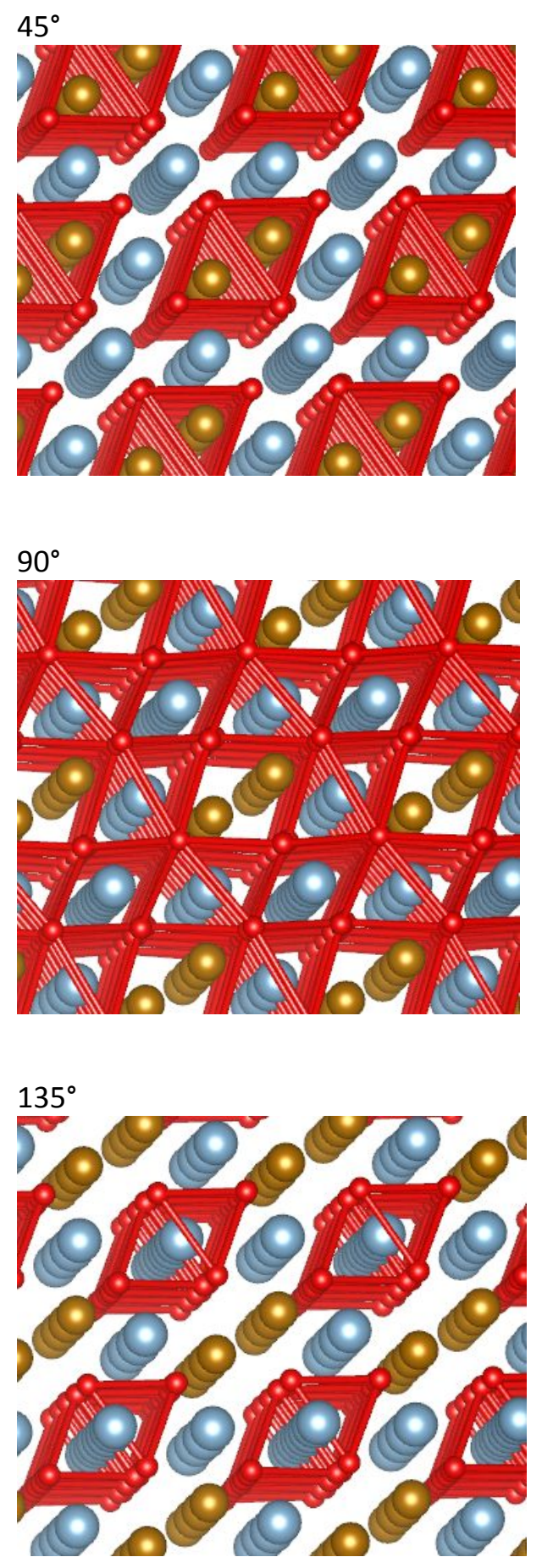

Figure S1: Illustration of available diffusion pathways for specified diffusion direction. Bonds are not depicted in this figure, instead shown are the potential diffusion pathways between $\mathrm{O}$ sites for a specific diffusion direction. For the $45^{\circ}$ and $135^{\circ}$ diffusion directions, the diffusion pathways into and out of the plane of this paper do not connect. 


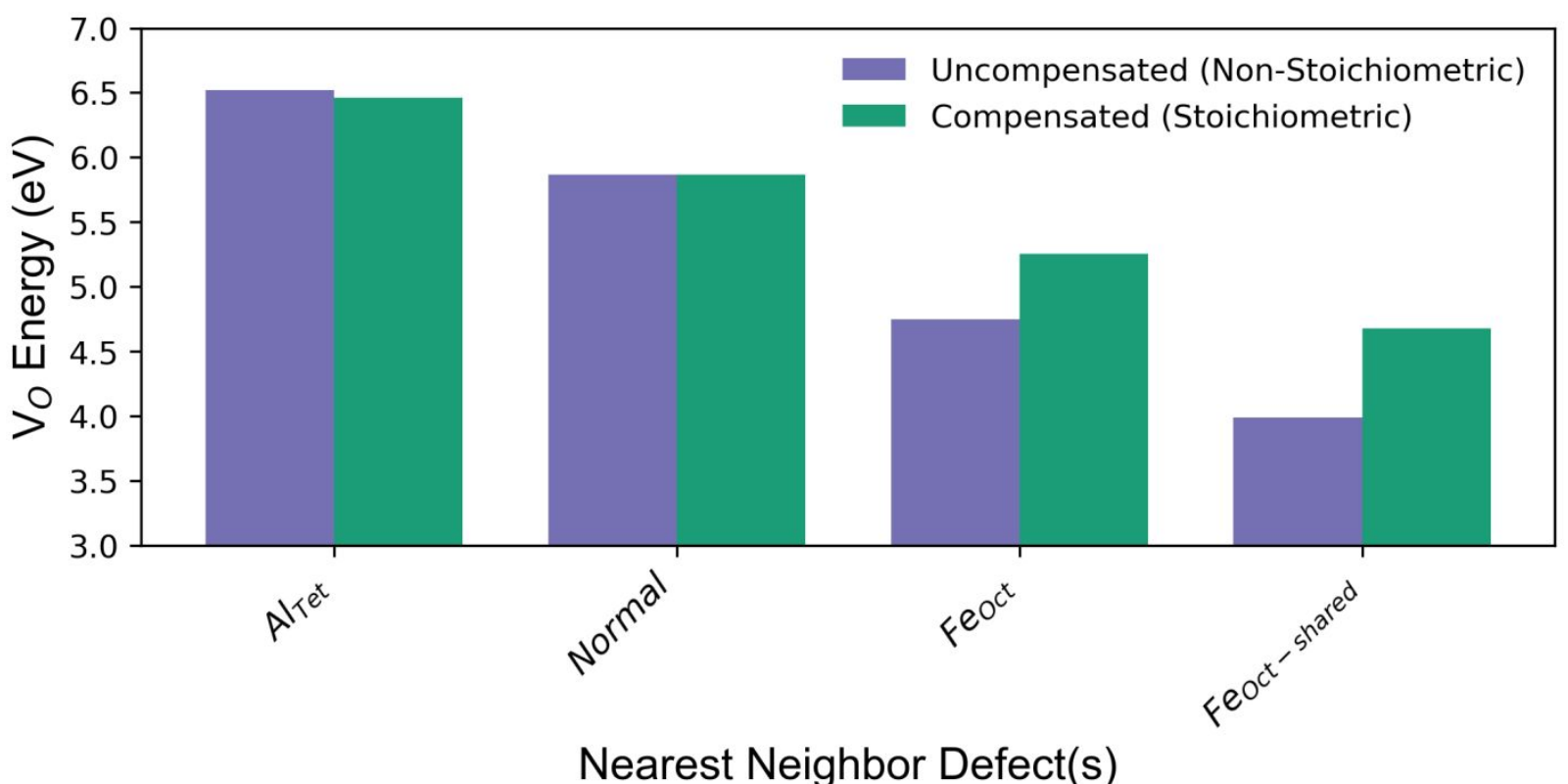

Figure S2: A comparison of compensated (purple) and uncompensated (green) $V_{O}$ formation energies. Uncompensated $\mathrm{Fe}_{\mathrm{Oct}}$ defects are lower in energy due to their redox flexibility. 


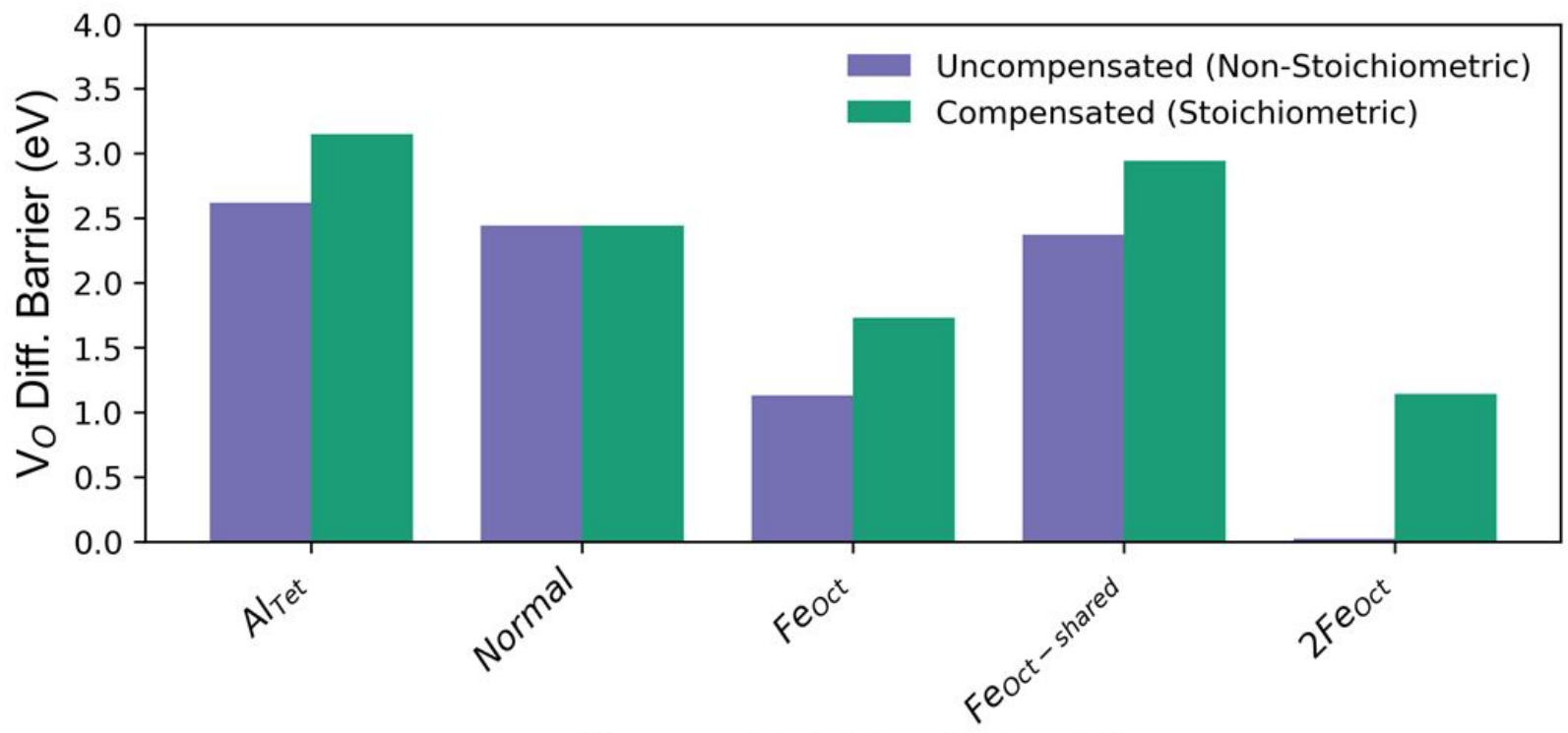

Nearest Neighbor Defect(s)

Figure S3: A comparison of compensated (purple) and uncompensated (green) $V_{0}$ diffusion barriers. Uncompensated defects are lower in energy in all cases. Notably the diffusion into the $2 \mathrm{Fe}_{\text {oct }}$ state occurs with negligible barrier. 


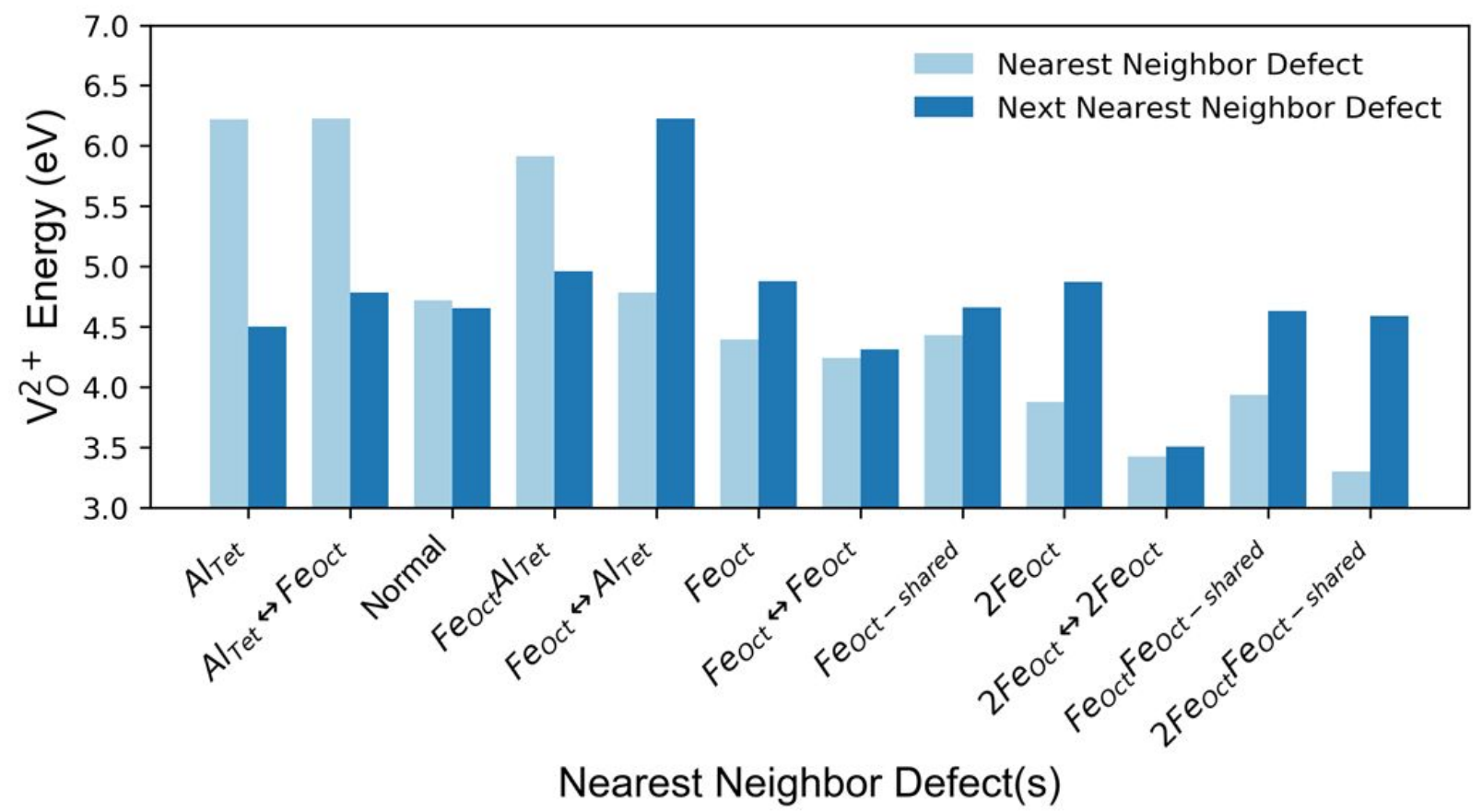

Figure S4: Charged $V_{0}$ formation energy (with $E_{f}=$ VBM) when directly neighboring the listed defect (light blue) and when next nearest neighbor to the listed defect (dark blue). If another defect is next nearest neighbor to the $V_{0}$, it is shown with a left-right arrow in the label. 


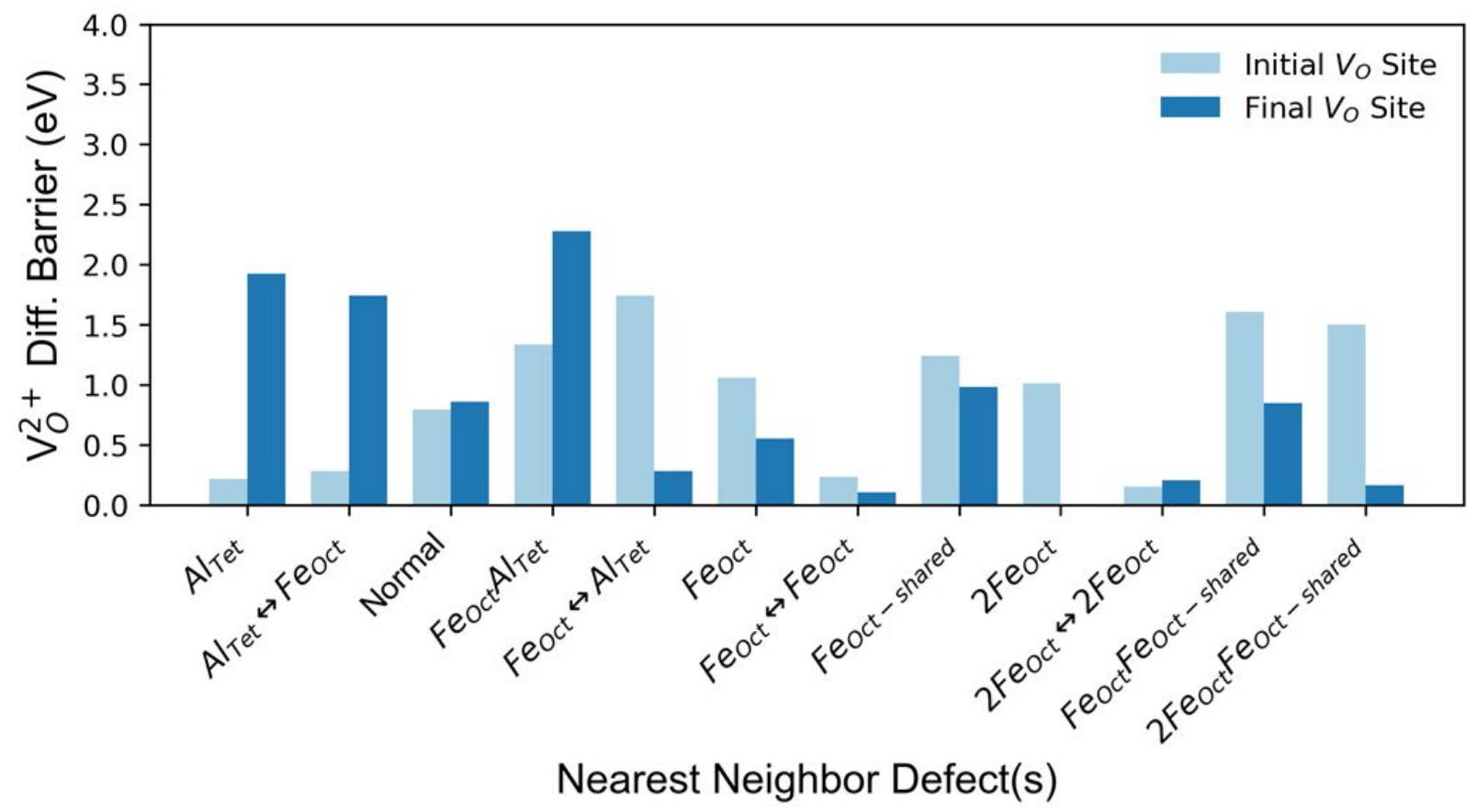

Figure S5: Charged $V_{O}$ diffusion barriers for inverse hercynite from and to the specified sites. If multiple sites are included diffusion is labeled relative to the defect site to the left of the double arrow $(\leftrightarrow)$. The light blue bar denotes diffusion from the specified defect site, and the dark blue bar denotes diffusion to the specified defect site. 
Table S1: $V_{0}$ formation energies and diffusion barriers for hercynite with a ferromagnetic spin configuration, and for hercynite in 5 quasirandom spin configurations generated using the special quasirandom structures method.

\begin{tabular}{|l|r|r|}
\hline System & $\begin{array}{l}\mathbf{V}_{\mathbf{O}} \text { Formation } \\
\text { Energy (eV) }\end{array}$ & $\begin{array}{l}\mathbf{V}_{\mathbf{O}} \text { Diffusion } \\
\text { Barrier (eV) }\end{array}$ \\
\hline Ferromagnetic & 5.87 & 2.46 \\
\hline SQS 1 & 5.94 & 2.41 \\
\hline SQS 2 & 5.86 & 2.33 \\
\hline SQS 3 & 5.83 & 2.51 \\
\hline SQS 4 & 5.81 & 2.31 \\
\hline SQS 5 & 5.95 & 2.32 \\
\hline SQS Avg. & 5.88 & 2.38 \\
\hline
\end{tabular}


Table S2: Site frequency for isolated $\mathrm{V}_{\mathrm{O}}$ at $\mathrm{X}=0.25$

\begin{tabular}{|l|l|}
\hline Site & Probability \\
\hline Normal & 0.50 \\
\hline $\mathrm{Fe}_{\text {oct }}$ & 0.22 \\
\hline $2 \mathrm{Fe}_{\text {oct }}$ & 0.03 \\
\hline $3 \mathrm{Fe}_{\text {oct }}$ & $<0.01$ \\
\hline $\mathrm{Al}_{\text {tet }}$ & 0.17 \\
\hline $\mathrm{Al}_{\text {tet }} \mathrm{Fe}_{\text {oct }}$ & 0.07 \\
\hline $\mathrm{Al}_{\text {tet }} 2 \mathrm{Fe}_{\text {oct }}$ & 0.01 \\
\hline $\mathrm{Al}_{\text {tet }} 3 \mathrm{Fe}_{\text {oct }}$ & $<0.01$ \\
\hline
\end{tabular}

